\title{
Prevention of balloon damage during initiation of intra-aortic balloon counterpulsation
}

\author{
Michael F. O'Rourke, Victor P. Chang, and Mark X. Shanahan \\ From the Cardiovascular Unit, St. Vincent's Hospital, Sydney, Australia
}

Damage to an intra-aortic balloon occurred on two occasions in 93 insertion procedures. The complication was recognized before gas embolization occurred, and neither patient suffered ill effects. On both occasions the balloon was holed when pinched by artery forceps applied to the 'dacron' graft.

Rupture of an intra-aortic balloon is the most obvious potential complication of arterial counterpulsation. The rarity of this event is a tribute to surgical care and to the design and construction of currently available intra-aortic counterpulsation systems. However, despite care in surgical technique, balloon rupture can occur during insertion of the catheter and could conceivably be lethal if not recognized immediately and if safety mechanisms are overridden during initiation of counterpulsation.

Balloon rupture occurred twice during 93 catheter insertion procedures by eight operators over four years. The balloon was damaged in the same way on both occasions when artery forceps were applied to the 'dacron' graft to assist in pulling this over the balloon onto the catheter shaft. Our experience is reported so that others may avoid the same error.

\section{Case 1}

\section{Case reports}

A 47-year-old man was admitted in cardiogenic shock and the decision was made to initiate counterpulsation. Difficulty was experienced in pulling the $8 \mathrm{~mm}$ I.D. 'dacron' graft over the $40 \mathrm{ml}$ balloon selected. Artery forceps were applied to the edge of the graft as it lay on the balloon and were used to complete the procedure. The catheter was inserted to the correct position using the technique described by Kantrowitz et al. (1968) and connected to the console. Before proceeding further, blood was detected in the catheter tubing. The catheter was removed and another inserted without incident and counterpulsation was started with good effect.

Received 30 December 1975.
The first catheter was found to have a small round defect, approximately $1 \mathrm{~mm}$ in diameter, in its balloon some $6 \mathrm{~cm}$ from the distal end. Observers suspected but could not be certain that artery forceps had nipped the balloon and torn the hole.

\section{Case 2}

A 55-year-old man was admitted in acute pulmonary oedema complicating myocardial infarction. Medical therapy was judged to have failed and the patient was prepared for counterpulsation. A $40 \mathrm{ml}$ balloon catheter was selected, and again difficulty was experienced in threading the balloon through the $8 \mathrm{~mm}$ 'dacron' graft. Again, artery forceps were applied to the graft as it lay on the balloon and the procedure was completed. The catheter was inserted and connected to the console. The catheter was purged with helium gas and counterpulsation was started with the safety switch in the manual mode. After some 15 to 20 seconds, blood was seen in the catheter tubing.

Counterpulsation was discontinued, the catheter was removed, and another introduced. The patient's condition did not change in any way. Counterpulsation was then restarted, with good effect. The original balloon catheter appeared intact but on testing under water, a small leak was detected in a position similar to that in Case 1. Microscopical examination showed the tear with accompanying marks that could only be attributed to the forceps.

\section{Discussion}

Damage to an intra-aortic balloon catheter by a sharp instrument has been described on one occasion (Scheidt et al., 1973). We have been meticulous with respect to sharp instruments and during the insertion procedures have not permitted 
these to be used near the balloon once it has been removed from its sheath. Damage from a blunt instrument is unexpected. On both occasions described here the arterial graft was grasped by the forceps as it lay on the redundant folds of the balloon and the balloon was inadvertently holed. This manoeuvre, which we consider to be dangerous, is shown in Fig. 1. Fig. 2 shows the recommended procedure for applying the arterial graft. The graft (which should be as wide and as short as practicable) is grasped at one end by at least three forceps before being applied to the balloon, then gently eased over the balloon. We urge that forceps never be applied to the graft once the graft has been placed on the balloon.

The complications described here were poten-

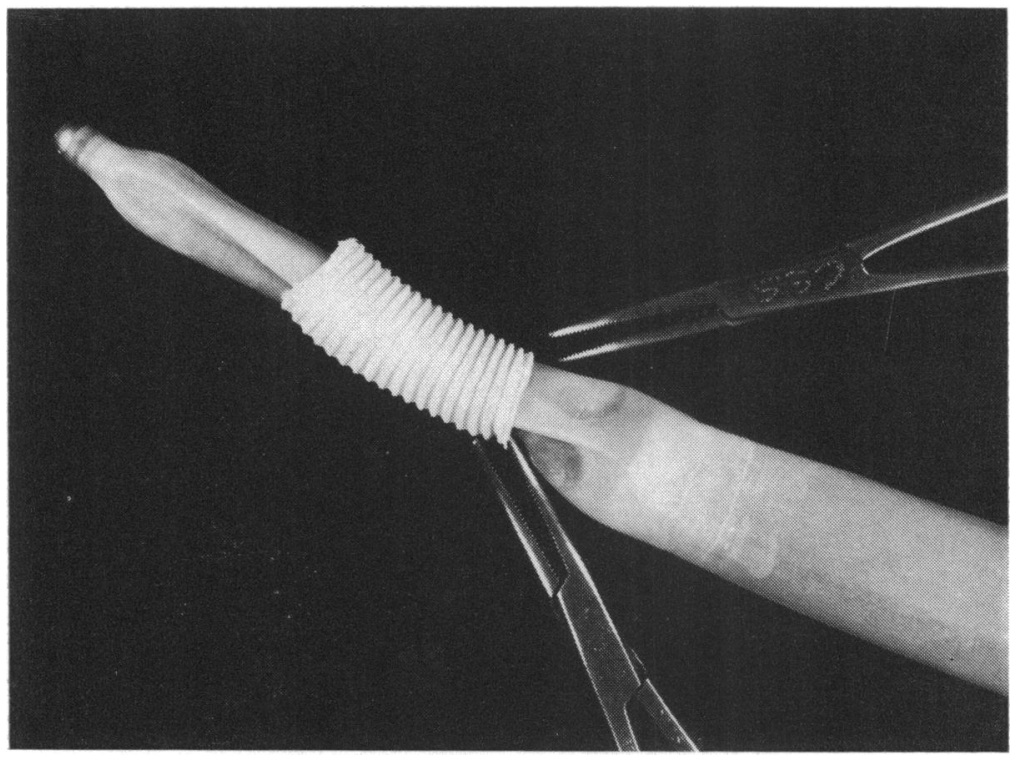

FIG. 1 The dangerous technique of graft placement.

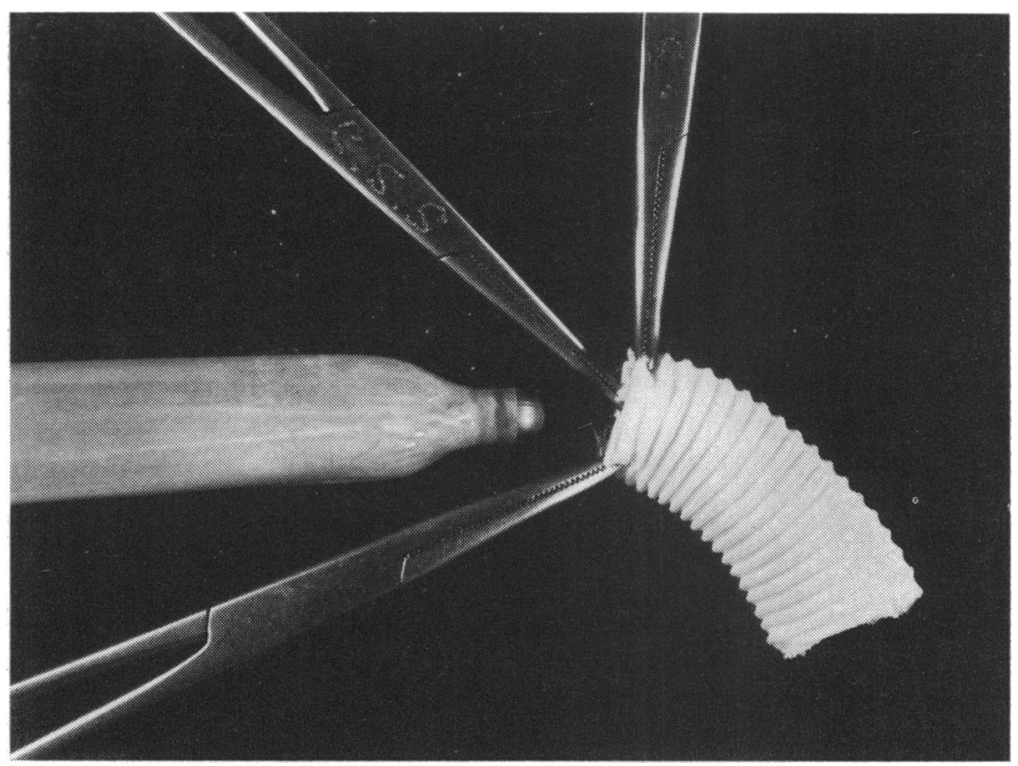

FIG. 2 The recommended technique of graft placement. 
tially the most serious we faced in four years' experience with intra-aortic counterpulsation. We report these complications trusting that they will be kept in proper perspective-complications that need not have occurred and in 93 desperately ill patients, the only immediately life-threatening side effects of an important new life-saving technique.

\section{References}

Kantrowitz, A., Phillips, S. J., Bunter, A. N., Tjonneland, S., and Haller, J. D. (1968). Technique of femoral artery cannulation for phase-shift balloon pumping. Fournal of Thoracic and Cardiovascular Surgery, 56, 219.

Scheidt, S., Wilner, G., Mueller, H., Summers, D., Lesch, M., Wolff, G., Krakauer, J., Rubenfire, M., Fleming, P., Noon, G., Oldham, N., Killip, T., and Kantrowitz, A. (1973). Intra-aortic balloon counterpulsation in cardiogenic shock. New England fournal of Medicine, 288, 979.

Requests for reprints to Dr. Michael F. O'Rourke, Professorial Department of Medicine, St. Vincent's Hospital, Darlinghurst, 2010, N.S.W., Australia. 